\title{
HUBUNGAN FUNGSI KOGNITIF DENGAN TINGKAT KEMANDIRIAN PADA LANSIA
}

\author{
Tia Ayu Adiningsih ${ }^{1 *}$, Tri Wahyuningsih², Mohamad Anwar ${ }^{3}$ \\ ${ }^{1}$ Mahasiswi STIKes Budi Luhur Cimahi \\ E-mail : t.ayu2450@gmail.com \\ ${ }^{2}$ Dosen STIKes Budi Luhur Cimahi \\ E-mail : trie.ners@gmail.com \\ ${ }^{3}$ Dosen STIKes Budi Luhur Cimahi \\ E-mail : anwar.76@gmail.com
}

Disubmit: 30 Desember $2021 \quad$ Diterima:31 Desember 2021
DOI: https://doi.org/10.33024/mnj.v1i1.5746

Diterbitkan: 03 Januari 2022

\section{ABSTRACT : THE CORRELATION OF COGNITIVE FUNCTION WITH THE LEVEL OF INDEPENDENCE OF THE ELDERLY}

Introduction: The increasing of elderly population will increase new problems in various fields. Some problems and disorders that often arise or occur in the elderly are decreased of cognitive function. The physical changes that have decreased will cause various life aspects interference that have big influence on the level of independence of the elderly, include the decline in cognitive function. The results of research that have been developed by several experts suggest that $50 \%$ of elderly with cognitive impairment will feel dependence on their caregiver or closest companion such as the family.

Objective: This research was to analyze the correlation between cognitive function and the level of independence of the elderly at RW 14 Public Health Center Cibeber.

Methods: The research used an analytical survey with a cross sectional approach. The sample in this research amounted to 88 respondents using purposive sampling technique. The data collection use the results of interview with the Mini-Mental State Exam (MMSE) and the Katz Index. Analysis of Kolmogorof-Smirnov test data using SPSS results.

Results: The results of this research were obtained with the results of the MMSE interview, most of (60.2\%) of elderly had normal cognitive function, most of (64.8\%) of elderly had a level of independence. The results of the analysis obtained ( $p$ value $=0.000<(0.005$ ) it means that there is a correlation between the two variables.

Conclusion: There is a correlation between the cognitive function of the elderly and the level of independence in the elderly at RW 14 Public Health Center of Cibeber Area. The family is expected to be able to prevent or reduce the impact of physical decline and psychology in the elderly.

Keywords: Elderly, Cognitive Function, Level of Independence.

\section{INTISARI: HUBUNGAN FUNGSI KOGNITIF DENGAN TINGKAT KEMANDIRIAN PADA LANSIA}

Pendahuluan: Semakin meningkatnya populasi lanjut usia maka akan meningkatkan masalah baru diberbagai bidang. Beberapa masalah dan gangguan yang sering muncul atau terjadi pada lansia adalah menurunnya fungsi kognitif. 
Perubahan fisik yang cenderung mengalami penurunan akan menyebabkan berbagai gangguan aspek kehidupan yang mempunyai pengaruh besar dalam tingkat kemandirian lansia, termasuk dalam penurunan fungsi kognitif. Hasil penelitian yang telah dikembangkan oleh beberapa ahli mengemukakan bahwa $50 \%$ lansia yang mengalami gangguan kognitif akan mengalami ketergantungan terhadap caregiver atau pendamping terdekatnya yaitu pihak keluarga.

Tujuan: Penelitian ini bertujuan untuk menganalisis hubungan fungsi kognitif dengan tingkat kemandirian lansia di wilayah Puskesmas Cibeber RW 14. Metode: Penelitian menggunakan survey analitik dengan pendekatan cross sectional. Sampel dalam penelitian ini berjumlah 88 responden dengan menggunakan teknik purposive sampling. Pengumpulan data menggunakan hasil wawancara dengan Mini-Mental State Exam (MMSE) dan Katz Index. Analisa data uji Kolmogorof-Smirnov menggunakan hasil SPSS.

Hasil: Hasil penelitian ini didapatkan dengan hasil wawancara MMSE sebagian besar $(60,2 \%)$ memiliki fungsi kognitif normal, sebagian besar $(64,8 \%)$ memiliki tingkat kemandirian mandiri. Hasil analisis didapatkan ( $\mathrm{p}$ value $=0,000<\mathrm{a}$ $(0,005)$ artinya ada hubungan antara dua variabel tersebut.

Kesimpulan: Terdapat hubungan antara fungsi kognitif lansia dengan tingkat kemandirian pada lansia di Wilayah Puskesmas Cibeber RW 14. Pihak keluarga diharapkan mampu melakukan pencegahan atau pengurangan dampak kemunduran fisik dan psikis pada lansia.

Kata kunci : Lansia, Fungsi Kognitif, Tingkat Kemandirian

\section{PENDAHULUAN}

World Health Organization (WHO) tahun 2010 mencatat penurunan kognitif lansia diperkirakan 121 juta manusia, dari jumlah itu 5,8\% lakilaki dan $9,5 \%$ perempuan didunia. Sekitar $50 \%$ dari seluruh populasi lansia di Indonesia menunjukkan penurunan kognitif sedangkan sisanya tetap memiliki kemampuan kognitif sama seperti usia muda (Wreksoatmodjo, 2014). Berdampak positif apabila, penduduk lansia berada dalam keadaan sehat, aktif dan produktif. Disisi lain, besarnya jumlah penduduk lansia menjadi beban jika lansia memiliki masalah penurunan kesehatan yang berakibat pada peningkatan disabilitas, tidak adanya dukungan sosial dan lingkungan yang tidak ramah terhadap penduduk lansia (Badan Pusat Statistik, 2015).(Heni Atiqah, 2020)

Pada umumnya gangguan fungsi kognitif merupakan kemunduran memori dan daya ingat yang dapat mempengaruhi aktifitas sehari-hari. Seperti penurunan fungsi fisik, ditandai dengan ketidakmampuan lansia untuk beraktifitas sehari-hari contohnya : makan, minum, mandi, berjalan, tidur, duduk, BAB, BAK, dan bergerak. Perubahan fisik yang cenderung mengalami penurunan ini akan menyebabkan berbagai gangguan secara aspek kehidupan yang mempunyai pengaruh besar dalam tingkat kemandirian lansia.(Mia Fatma Ekasari, 2018)

Faktor resiko yang mempengaruhi lanjut usia terkena gangguan kognif yaitu : usia semakin tua maka secara alamiah akan terjadi apoptosis pada sel neuron yang berakibat terjadinya atropi pada otak yang dimulai dari atropi korteks, atropi sentral, hiperintensitas substantia alba dan paraventrikuler. Sehingga dapat mengakibatkan penurunan fungsi kognitif seseorang. Depresi, stress dan ansietas akan menyebabkan penurunan kecepatan aliran darah 
dan stress memicu pelepasan hormon glukokortikoid yang dapat menurunkan fungsi kognitif. Jenis kelamin wanita lebih beresiko mengalami penurunan kognitif. (Mia Fatma Ekasari, 2018)

Kemandirian merupakan sikap individu yang diperoleh secara komulatif dalam perkembangan dimana individu akan terus belajar untuk bersikap mandiri dalam menghadapi berbagai situasi dilingkungan, sehingga individu mampu berpikir dan bertindak sendiri. Menurut Husain (2013), dengan kemandirian seseorang dapat memilih jalan hidupnya untuk berkembang ke yang lebih mantap.(Mia Fatma Ekasari, 2018)

Rasio ketergantungan penduduk Lansia di Indonesia pada tahun 2015 sebesar 13,28. Dibanding daerah perkotaan, penduduk usia produktif di pedesaan lebih banyak menanggung kehidupan penduduk lansia. Hal ini terlihat dari rasio ketergantungan penduduk lansia di pedesaan lebih tinggi dari pada di perkotaan yaitu sebesar 14,66 (Statistik, 2015). Menurut Kemenkes RI (2013) angka rasio $11,90 \%$ menunjukkan bahwa setiap 100 orang penduduk usia produktif harus menanggung sekitar 12 orang penduduk lansia. Namun bila dibandingkan perjenis kelamin, angka rasio ketergantungan

\section{METODE}

Penelitian ini menggunakan rancangan penelitian survey analitik dengan desain cross sectional. Populasi dari penelitian ini adalah 88 lansia di Wilayah Kerja Puskesmas Cibeber RW 14. Sampel yang digunakan dalam penelitian ini adalah 88 yang memenuhi kriteria inklusi dan kriteria eklusi di Wilayah Kerja Puskesmas Cibeber RW 14. Penelitian ini menggunakan total sampling. instrument penelitian ini menggunakan Pedoman wawancara penduduk lansia perempuan lebih tinggi dibandingkan dengan penduduk lansia laki-laki (12,95\% berbanding 10,86\%). Dengan meningkatnya populasi jumlah lansia yang terus tumbuh akan meningkatkan angka beban ketergantungan lansia.(Mia Fatma Ekasari, 2018)

Menurut Mongisidi R (2013 dalam Manurung dkk, 2016) penyebab terbesar terjadinya ketergantungan terhadap orang lain untuk merawat diri sendiri akibat ketidakmampuan dalam melakukan aktivitas seharihari merupakan akibat dari penurunan fungsi kognitif pada lansia. Hal ini disebabkan karena kognitif sangat berperan dalam kemampuan lansia untuk mengontrol dirinya. (Chandra H. Manurung, 2016)

Dari hasil studi pendahuluan dengan kader RW 14 menyatakan bahwa untuk pemeriksaan tingkat kemandirian di wilayah kerja Puskesmas Cibeber sendiri sudah dilaksanakan di RW 14 dengan hasil tingkat kemandirian kategori $A$ sebanyak 57 jiwa, kategori B sebanyak 18 jiwa, kategori $C$ sebanyak 13 jiwa. Berdasarkan uraian latar belakang diatas, maka peneliti tertarik untuk melakukan penelitian dengan judul "Hubungan Fungsi Kognitif Dengan Tingkat Kemandirian Pada Lansia"

Mini-Mental State Exam (MMSE) dan Barthel Index. Sebelum pengambilan data peneliti memberikan penjelasan kepada responden mengenai tujuan, manfaat, dan prosedur penelitian serta diminta persetujuan. Analisa data yang digunakan adalah uji statistic dengan uji Kolmogorof-Smirnov. Skala yang digunakan adalah skala ordinal. Data tersebut kemudian akan dihitung dengan SPSS dengan derajat kemaknaan $\alpha=0,005$. 
HASIL :

1. Tabel 1 Gambaran Fungsi Kognitif Pada Lansia Di Wilayah Kerja Puskesmas Cibeber (RW 14)

\begin{tabular}{lll}
\hline Fungsi Kognitif & $\begin{array}{l}\text { Frekuensi } \\
\text { (f) }\end{array}$ & Persentase (\%) \\
\hline Normal & 53 & 60,2 \\
Sedang (Probable) & 35 & 39,8 \\
Berat (Definitif) & 0 & 0 \\
\hline Total & 88 & 100 \\
\hline Sumber: Data Primer 2021 &
\end{tabular}

Berdasarkan hasil penelitian pada tabel 1 tentang fungsi kognitif pada lansia di wilayah kerja Peskesmas Cibeber (RW 14) dari 88 responden, sebagian besar yaitu 53 responden $\quad(60,2 \%) \quad$ memiliki gangguan kognitif baik dan hampir setengahnya yaitu 35 responden $(39,8 \%)$ memiliki gangguan kognitif sedang.

2. Tabel 4. 2 Gambaran Tingkat Kemandirian Pada Lansia Di Wilayah Kerja Puskesmas Cibeber (RW 14)

\begin{tabular}{lll}
\hline Tingkat Kemandirian & $\begin{array}{l}\text { Frekuensi } \\
\text { (f) }\end{array}$ & Persentase (\%) \\
\hline Mandiri & 57 & 64.8 \\
Ketergantungan Ringan & 14 & 15.9 \\
Ketergantungan Sedang & 10 & 11.4 \\
Ketergantungan Berat & 7 & 8.0 \\
Ketergantungan Total & 0 & 0 \\
\hline Total & 88 & 100 \\
\hline \multicolumn{2}{c}{ Sumber: Data Primer 2021 }
\end{tabular}

Berdasarkan hasil penelitian pada tabel 2 tentang tingkat kemandirian pada lansia di wilayah kerja Peskesmas Cibeber (RW 14) dari 88 responden, sebagian besar yaitu 57 responden $(64,8 \%)$ memiliki tingkat kemandirian normal, sebagian kecil yaitu 14 responden $(15,9 \%)$ memiliki tingkat

3. Tabel 3 Hubungan Fungsi Kognitif Dengan Tingkat Kemandirian Pada Lansia di Wilayah Kerja Puskesmas Cibeber (RW 14)

\section{Fungsi Kognitif Tingkat Kemandirian}

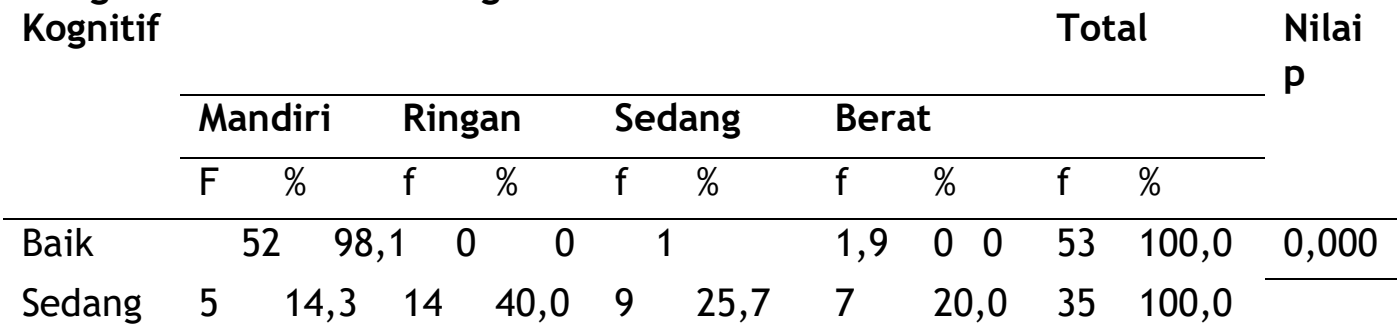

$\begin{array}{lllllllllll}\text { Total } & 57 & 64,8 & 14 & 15,9 & 10 & 11,4 & 7 & 8,0 & 88 & 100,0\end{array}$ kemandirian ringan, sebagian kecil yaitu 10 responden $(11,4 \%)$ memiliki tingkat kemandirian sedang, dan sebagian kecil yaitu 7 responden $(8,0 \%)$ memiliki tingkat kemandirian berat serta tidak seorangpun responden dalam kategori kemandirian total.

Sumber : Data Primer 2021 
Berdasarkan tabel 3 diatas diperoleh hasil analisis tentang hubungan fungsi kognitif dengan tingkat kemandirian pada lansia yaitu 88 responden terdapat 53 responden yang kognitifnya baik, dimana ada 52 atau seluruhnya $(98,1 \%)$ dengan tingkat kemandiriannya mandiri, dan sebagian kecil yaitu 1 responden $(1,9 \%)$ dengan tingkat kemandiriannya sedang, serta tidak ada seorangpun yang tingkat kemandiriannya ringan dan berat.

Pada responden yang

memiliki gangguan kognitif sedang yaitu 5 responden atau sebagian

\section{PEMBAHASAN :}

\section{Fungsi Kognitif}

Berdasarkan hasil penelitian fungsi kognitif pada lansia di wilayah kerja Peskesmas Cibeber (RW 14) dari 88 responden, 53 responden atau hampir seluruhnya $(60,2 \%)$ memiliki fungsi kognitif baik dan 35 responden atau hampir setengahnya $(39,8 \%)$ memiliki gangguan kognitif ringan. Fungsi kognitif meliputi perhatian, kemampuan bahasa, memori, proses belajar, pemahaman dan lain-lain sehingga menyebabkan reaksi dan perilaku lansia menjadi lambat.

Hasil penelitian ini sesuai dengan teori yang dikemukakan Elisa Anderson (2017) menyatakan bahwa kognitif yang dimiliki oleh lansia adalah suatu proses mental dengan suatu interaksi, yaitu prilaku, daya ingat, kemampuan persepsi dan sensori, atensi, serta kemampuan komunikasi yang dimiliki lansia untuk menjalankan perannya dimasyarakat serta lingkungannya.

Pada penelitian ini didapatkan sebagian besar lansia di wilayah kerja Peskesmas Cibeber (RW 14) mempunyai fungsi kognitif baik hal ini terjadi karena lansia melakukan aktivitas sehari-hari secara rutin dan kecil (14,3\%) dengan tingkat kemandiriannya mandiri, hampir setengahnya yaitu 14 responden $(40,0 \%)$ dengan tingkat kemandirian ringan, sebagian kecil 9 responden $(25,7 \%)$ dengan tingkat kemandirian sedang dan 7 responden $(20,0 \%)$ dengan tingkat kemandirian berat.

Berdasarkan uji KolmogorofSmirmov dengan tabel $2 \times 4$ diperoleh hasil $p$ value $=0,000<a(0,05)$, dinyatakan Ho ditolak artinya ada Hubungan Fungsi Kognitif Dengan Tingkat Kemandirian Pada Lansia di Wilayah Kerja Puskesmas Cibeber (RW 14).

berkala yang membuat fungsi kognitif lansia lebih baik, dilihat dari lansianya yang masih aktif dalam bekerja dan melakukan kegiatan berjemur, dan jalan pagi. Lansia di wilayah kerja Peskesmas Cibeber (RW 14) masih aktif mengikuti pengajian menjadikan salah satu faktor yang dapat menstimulasi fungsi kognitif dimana lansia bisa bersosialisasi dengan yang lainnya.

Penurunan fungsi kognitif dapat dihambat dengan melakukan tindakan preventif. Salah satu tindakan preventif yaitu dengan memperbanyak aktivitas fisik. Aktivitas fisik diduga dapat menstimulasi pertumbuhan saraf yang kemungkinan dapat menghambat penurunan fungsi kognitif pada lansia. Lansia mengalami penurunan fungsi kognitif seiring dengan pertambahnya usia, penurunan fungsi kognitif juga dapat dicegah dengan memaksimalkan daya kerja otak.

\section{Tingkat Kemandirian}

Berdasarkan hasil penelitian tentang tingkat kemandirian pada lansia di wilayah kerja Puskesmas Cibeber (RW 14) dari 88 responden $64.8 \%$ mempunyai tingkat 
kemandirian mandiri, $(15,9 \%)$ yaitu 14 responden memiliki tingkat kemandirian ringan, sebagian kecil $(11,4 \%)$ yaitu 10 responden memiliki tingkat kemandirian sedang, dan sebagian kecil $(8,0 \%)$ yaitu 7 responden memiliki tingkat kemandirian berat. Kemandirian merupakan kebebasan untuk bertindak, tidak tergantung pada orang lain, tidak terpengaruh pada orang lain dan bebas mengatur diri sendiri atau aktivitas seseorang baik individu maupun kelompok dari berbagai kesehatan atau penyakit.(Mia Fatma Ekasari, 2018) Tingkat kemandirian lansia dipengaruhi oleh aktivitas seharihari yang dilakukan oleh lansia, semakin banyak aktivitas yang dilakukan maka semakin kecil kemungkinan lansia akan mengalami penurunan fungsi kognitif. Aktivitas dapat bermanfaat untuk mempertahankan fungsi sendi pada lansia. [20]

Hasil penelitian di wilayah kerja Puskesmas Cibeber (RW 14) menunjukkan bahwa lansia yang mandiri kebanyakan tinggal serumah dengan keluarganya dan mengasuh cucunya, lansia bisa makan, mandi, berdandan, berpindah tempat sendiri, menaiki tangga bahkan para lansia kebanyakan masih bekerja, aktif dalam melakukan aktivitas sehari-hari seperti berjemur, berjalan pagi hari, serta mengikuti pengajian. Hal ini terjadi karena adanya motivasi hidup lansia yang masih tinggi serta keinginannya untuk menjadi lansia produktif.

Hasil penelitian menunjukkan sebagian besar lansia mandiri dalam melakukan aktivitas sehari-harinya yaitu makan, mandi, berdandan, ke toilet, berjalan dipermukaan datar dan menaiki tangga. Aktivitas juga dapat memperbaiki kualitas hidup seseorang melalui peningkatan kebugaran dan perbaikan rasa sehat (Ferrini \& Ferrini 2008).

\section{Hubungan Fungsi Kognitif dengan \\ Tingkat Kemandirian pada Lansia}

Berdasarkan tabel 4.3 hasil penelitian tentang hubungan fungsi kognitif dengan tingkat kemandirian pada lansia di RW 14 dari 88 responden terdapat 53 responden yang memiliki fungsi kognitif baik dan tingkat kemandirian mandiri sebanyak 52 responden $(98,1 \%)$, dan lansia mengalami fungsi kognitif baik dengan tingkat kemandirian sedang sebanyak 1 responden (1,9\%). Hal ini terjadi karena adanya faktor lain seperti diabetes melitus, hipertensi sehingga lansia memiliki ketergantungan sedang. Selain itu tingkat pendidikan juga dapat pengaruh utama dalam penurunan fungsi kognitif. Pendidikan merupakan salah satu faktor penting dalam mencegah terjadinya penurunan fungsi kognitif. ${ }^{[11]}$

Hasil uji statistik dengan pengujian Kolmogorof-Smirnov didapatkan nilai $\mathrm{p}$ value $0,000<\mathrm{a}$ $(0,005)$ maka $\mathrm{Ha}$ diterima dan $\mathrm{Ho}$ ditolak sehingga dapat disimpulkan ada hubungan fungsi kognitif dengan tingkat kemandirian pada lansia di wilayah kerja Puskesmas Cibeber RW 14. Hasil ini menunjukan bahwa fungsi kognitif merupakan salah satu faktor yang dapat mempengaruhi tingkat kemandirian. Gangguan aspek-aspek dari fungsi kognitif dapat mengganggu dalam berpikir logis dan menghambat tingkat kemamdirian dalam melakukan aktivitas sehari-hari.

Dalam penelitian ini peneliti mengkaji bagaimana fungsi kognitif berdampak pada kemandirian pada lansia. Sebagian besar lansia di wilayah kerja Puskesmas Cibeber RW 14 yang fungsi kognitifnya baik dapat melakukan aktivitas sehari-hari seperti mandi, berpakaian rapi, pergi ke toilet, berpindah tempat, dapat mengontrol BAK atau BAB, serta dapat makan sendiri. Dan dapat melakukan aktivitas sehari- 
hari secara rutin dan aktif dalam melakukan gerak jalan setiap paginya sehingga dapat menstimulus fungsi kognitifnya dengan cara berkomunikasi dengan yang lainnya.

Hasil penelitian yang dilakukan oleh peneliti menunjukkan bahwa lansia yang memiliki fungsi kognitif baik memiliki kemandirian yang baik. Hal ini sesuai dengan penelitian yang dikembangkan oleh Sauliyusta \& Rekawati (2016) yaitu ada hubungan yang signifikan antara tingkat aktivitas fisik dengan fungsi kognitif pada lansia $(p=0,000)$. Tingkat aktivitas fisik ini mewakili kemampuan lansia dalam melakukan kegiatan sehari-hari atau tugas hariannya dan itu merujuk kepada kemandirian lansia.

Pada saat lansia memiliki gangguan fungsi kognitif, seperti penurunan kemampuan mengingat, kemampuan berbahasa, Dengan demikian, status kognitif dapat menjadi prediktor yang baik dari kemandirian fungsional dalam aktivitas sehari-hari pada lansia. (Heiman Nazari, 2015) Hal ini menunjukkan bahwa pada responden yang fungsi kognitifnya baik kecendrungan pada kemampuan aktivitas sehari-hari lebih mandiri. Lanjut usia yang memiliki fungsi kognitif yang normal yaitu mempunyai tingkat intelegensi dan memoriyang baik diimbangi dengan kondisifisik yang masih bugar sehingga setiap aktivitas dapat dikerjakan sendiri tanpa harus meminta bantuan dari orang lain. Fungsi kognitif yang baik pada lansia ternyata dapat menopang kondisi fisiknya sehingga tidak terlihat rentan.

Sedangkan penelitian yang dilakukan oleh Marlina,dkk pada (2017) di Kelurahan Tunggul Wulung Kota Malang dengan hasil penelitian dilihat sebagian besar $(63,6 \%)$ lansia memiliki fungsi kogitif sedang dan sebagian besar $(57,6 \%)$ kemandirian lansia masuk kategori mandiri. (Marlina, 2017) Hal ini dapat dilihat bahwa fungsi kognitif mempengaruhi kemampuan lansia dalam melakukan aktivitas normal sehari-hari baik aktivitas fisik maupun aktivitas secara sosial.

Pada masa lanjut usia seseorang akan mengalami beberapa perubahan dalam segi fisik, kognitif, maupun dalam kehidupan psikososialnya. Salah satunya aspek kognitif sangat berpengaruh terhadap kemampuan lansia dalam melakukan aktivitasnya. Lanjut usia yang mengalami perubahan fungsi kognitif berpengaruh terhadap kemandirian lansia. Hal ini disebabkan karena kemampuan daya ingat ini terkait dengan kemampuan lansia untuk mengingat masalalunya serta kejadian yang telah lampau dan berkaitan dengan kemampuan lansia membuat kalkulasi terhadap suatu hal seperti berhitung dan sebagainya. Kemunduran kemunduran ini pada akhirnya berakibat pada kemunduran kemampuan lanjut usia untuk melakukan aktivitas sehari-hari.

Fungsi kognitif yang baik dapat membuat lansia mampu melakukan aktivitas secara mandiri, baik secara fisik maupun aktivitas sosial seharihari, tanpa bergantung pada orang lain. Hal ini karena dapat mempertahankan aliran darah yang optimal dan mengantarkan nutrisi ke otak.

Pada penelitian ini terlihat bahwa lansia yang memiliki fungsi kognitif baik akan memiliki kemandirian yang baik. Kondisi ini sesuai dengan teori yang dikembangkan orem yaitu fokus utama dari model konseptual ini adalah kemampuan seseorang untuk merawat dirinya sendiri secara mandiri sehingga tercapai kemampuan untuk mempertahankan kesehatan dan kesejahteraannya. Berkaitan dengan penelitian bahwa yang diambil adalah teori 
ketergantungan keperawatan dimana mengacu pada perawatan yang diberikan kepada seseorang yang karena usia atau faktor yang berhubungan, tidak dapat melakukan perawatan diri sendiri yang diperlukan untuk mempertahankan hidup, memfungsikan kesehatan melanjutkan pengembangan pribadi dan kesejahteraan. ${ }^{[12]}$

\section{KESIMPULAN DAN SARAN \\ Kesimpulan :}

Berdasarkan pembahasan dari hasil penelitian yang berjudul hubungan fungsi kognitif dengan tingkat kemandirian pada lansia di wilayah kerja Puskesmas Cibeber RW 14 yang dilakukan pada tanggal 2230 Agustus. Maka peneliti dapat mengambil kesimpulan sebagai berikut :

1. Pada bagian Fungsi Kognitif Pada Lansia di Wilayah Kerja Puskesmas Cibeber (RW 14) dari 88 responden sebagian besar memiliki fungsi kognitif normal yaitu 53 responden $(60,2 \%)$.

2. Pada bagian Tingkat Kemandirian Pada Lansia di Wilayah Kerja Puskesmas Cibeber (RW 14) dari 88 responden kurang dari setengahnya memiliki tingkat kemandiriannya mandiri yaitu 57 responden $(64,8 \%)$.

3. Ada Hubungan Fungsi Kognitif dengan Tingkat Kemandirian Pada Lansia di Wilayah Kerja Puskesmas Cibeber (RW 14) ( $p$ value $=0,000<a(0,005)$.

\section{Saran}

1. Bagi STIKes Budi Luhur Cimahi

Disarankan kepada pihak institusi Pendidikan dapat meningkatkan program edukasi seperti melatih senam otak, terapi puzzle, terapi teka teki silang, terapi buku harian, terapi mencocokan kartu, ke masyarakan oleh mahasiswa atau dosen keperawatan saat melakukan praktik lapangan sebagai upaya pencegahan gangguan fungsi kognitif.

2. Bagi Masyarakat RW 14

Diharapkan kepada tokoh masyarakat setempat untuk melakukan upaya preventif jangka panjang dengan mengadakan senam otak, terapi puzzle, senam otak, terapi puzzle, terapi teka teki silang, terapi buku harian, terapi mencocokan kartu setiap minggunya. Sedangkan untuk jangka pendeknya bisa dengan cara mengingat aktivitasaktivitas sebelumnya yang telah dilakukan oleh lansia.

3. Bagi Peneliti Selanjutnya

Diharapkan bagi peneliti selanjutnya dapat lebih mengembangkan penelitian ini sehingga dapat mengetahui apa saja faktor-faktor yang mempengaruhi fungsi kognitif pada lansia seperti usia, pendidikan, dan pekerjaan masa lalu.

4. Bagi Puskesmas Cibeber

Hasil penelitian ini dapat dijadikan sebagai evaluasi atau kebijakan oleh puskesmas untuk menambah program yang ada misalnya melakukan senam otak, terapi puzzle, terapi teka teki silang, terapi buku harian, terapi mencocokan kartu, disetiap minggunya agar lansia yang mengalami fungsi kognitif sedang tidak menjadi berat. Sedangkan untuk jangka pendeknya bisa dengan cara mengingat aktivitas-aktivitas sebelumnya yang telah dilakukan oleh lansia. 


\section{DAFTAR PUSTAKA}

Arikunto. (2013). Prosedur Penelitian Kesehatan, Jakarta: Rineka Cipta.

Chandra H. Manurung, W. K., Junita Maja P. S. (2016). Gambaran fungsi kognitif pada lansia di Desa Koka Kecamatan Tombulu e-Clinic (eCl), 4.

Donsu.T.D.J. (2017). Metodologi Penelitian Keperawatan, Yogyakarta: Pustaka Baru Press.

Notoatmodjo. Metodologi Penelitian Kesehatan, Jakarta: Rineka Cipta.

Nursalam. (2017). Metodologi Penelitian Ilmu Keperawatan, Jakarta.

Widyanto. C. F. (2014). Keperawatan Komunitas Dengan Pendekatan Praktis, Yogyakarta: Nuha Medika.

Riyanto. (2011) Buku Ajar Metodologi Penelitian, Jakarta: EGC.

Heiman Nazari, V. R. d. (2015). Relationship Between Cognitive Status And Activities of Daily Living Among The Elderly Of Nursing Homes. Of Kermanshah University Of Medical Sciences, 12, 18.

Heni Atiqah, S. A. L. (2020). HUBUNGAN FUNGSI KOGNITIF LANSIA DENGAN TINGKAT KEMANDIRIAN LANSIA ILMIAH KESEHATAN RUSTIDA, 7, 107 - 114

Marlina, S. M., Ani Sutriningsih. (2017). Hubungan Fungsi Kognitif Dengan Tingkat
Kemandirian Lansia

Dalam Melakukan

Aktivitas Sehari-Hari Di

Kelurahan Tunggul

Wulung Kota Malang.

Jurnal Ilmiah

Keperawatan 2(1), 380390.

Mia Fatma Ekasari, N. M. R., Tien Hartini. (2018). Meningkatkan Kualitas Hidup Lansia. Wineka Media. 